\title{
Decarbonylation of the 2-Hydroxypyridine Radical Cation: A Computational Study
}

\author{
Joong Chul Choe \\ Department of Chemistry, Dongguk University-Seoul, Seoul 100-715, Korea.E-mail: jcchoe@dongguk.edu \\ Received May 11, 2014, Accepted June 23, 2014
}

\begin{abstract}
The potential energy surface (PES) for the dissociation of the 2-hydroxypyridine (2-HP) radical cation was determined from G3//B3LYP calculations, including the loss of $\mathrm{CO}, \mathrm{HCN}$, and $\mathrm{HNC}$. The formation of the $1 \mathrm{H}$ pyrrole radical cation by decarbonylation through a more stable tautomer, the 2-pyridone (2-PY) radical cation, was the most favorable dissociation pathway. Kinetic analysis by the Rice-Ramsperger-Kassel-Marcus model calculations was carried out based on the obtained PES. It is proposed that the dissociation occurs after a rapid tautomerization to $\mathbf{2}-\mathbf{P Y}{ }^{++}$, and that most of the ions generated by ionization of 2-HP have the structure of 2$\mathbf{P Y}^{*+}$ at equilibrium above the tautomerization barrier.
\end{abstract}

Key Words : 2-Pyridone ion, Potential energy surface, G3 calculation, RRKM calculation, Kinetics

\section{Introduction}

The keto-enol tautomerizations both between 2-hydroxypyridine (2-HP) and 2-pyridone (2-PY) and between their radical cations have been studied using various experimental and theoretical methods. ${ }^{1-5}$ In the gas phase, 2-HP is slightly more stable than 2-PY, while the 2-HP radical cation (2$\mathbf{H P}^{\mathbf{P}^{+}}$) is less stable than the 2-pyridone radical cation (2$\mathbf{P Y}^{\circ+}$ ). The reaction pathways for the tautomerizations occurring by $1,3-\mathrm{H}$ shift have been well established for both neutral and ionic systems.

The loss of $\mathrm{CO}$ is the predominant channel in the primary dissociation of $\mathbf{2}-\mathbf{H P}^{+\mathbf{+}}$, whereas the losses of $\mathrm{CO}$ and $\mathrm{HCN}$ (or $\mathrm{HNC}$ ) are competitive in the primary dissociations of both the 3- and 4-hydroxypyridine radical cations (3- and 4$\left.\mathbf{H P}^{++}\right){ }^{1,6}$ It has been proposed that the product ion by loss of CO from $\mathbf{2}-\mathbf{H P}^{++}$has the structure of the $1 H$-pyrrole radical cation $\left(\mathbf{P R}^{++}\right)$in a collision-induced dissociation (CID) study. ${ }^{7}$

Baldwin and Langley suggested that only an insignificant amount of 2-PY ${ }^{\circ+}$ is formed by electron ionization (EI) of 2HP, based on detection of one-component metastable peak for the loss of CO from $\mathbf{2}-\mathbf{H P}^{++} .8$ Trikoupis et al. used theoretical calculations to propose a dissociation pathway for the formation of $\mathbf{P R}^{\mathbf{}^{+}}+\mathrm{CO}$ from $\mathbf{2}-\mathbf{H} \mathbf{P}^{++}$, which occurs after the tautomerization to a more stable isomer, 2-PY ${ }^{+}{ }^{1}$ However, the transition state (TS) for the dissociation step was not located, preventing more accurate kinetic prediction for the dissociation. They called for further computational study at a high level of theory. A recent combined experimental and computational study by Jobst et al. ${ }^{9}$ proposed that the product ion formed by the loss of $\mathrm{CO}$ from $\mathbf{4}-\mathbf{H P}^{++}$has the vinyl(iso)ketenimine structure, not the $3 H$-pyrrole structure that had been proposed previously from the aforementioned CID study. ${ }^{7}$

Our theoretical studies of the radical cations of pyridine, ${ }^{10}$ and isomeric methylpyridines ${ }^{11,12}$ revealed that ring expansion, contraction, and opening played important roles in their dissociations. In the present work, we theoretically examine the dissociation pathways of $\mathbf{2}-\mathbf{H P}^{\mathbf{+}}$, including the loss of $\mathrm{CO}, \mathrm{HNC}$, and HCN. Quantum chemical calculations are used to construct the potential energy surface (PES) for the dissociation. The dissociation kinetics is investigated by applying the obtained PES to Rice-Ramsperger-KasselMarcus (RRKM) model ${ }^{13}$ calculations in order to estimate the rate constants.

\section{Computational Methods}

The geometries of the local minima were optimized at the B3LYP level of the density functional theory using the 6$31 \mathrm{G}(\mathrm{d})$ basis set. The TS geometries were examined and checked by calculating the intrinsic reaction coordinates (IRCs) at the same level. To improve the accuracy of the energies, the Gaussian-3 (G3) theory calculations using the B3LYP density functional method (G3//B3LYP $)^{14}$ were performed. In G3//B3LYP calculations, the geometries are obtained at the B3LYP/6-31G(d) level, and the zero point vibrational energies are obtained at the same level and scaled by a factor of 0.96 . All the other steps remain the same as in the G3 method, ${ }^{15}$ with the exception of the values of the higher-level correction parameters. All the calculations were performed with the Gaussian 09 program package. ${ }^{16}$

The RRKM expression was used to calculate the rate constants for selected unimolecular reaction steps: ${ }^{17}$

$$
k(E)=\frac{\sigma N^{*}\left(E-E_{0}\right)}{h \rho(E)}
$$

In this equation, $E$ is the reactant internal energy, $E_{0}$ the activation energy of the reaction, $N^{*}$ the sum of the TS states, $\rho$ the density of the reactant states, $\sigma$ the reaction path degeneracy, and $h$ Planck's constant. $N^{*}$ and $\rho$ were evaluated through a direct count of the states using the Beyer-Swinehart algorithm. ${ }^{18}$

The G3//B3LYP energies were used for the $E_{0}$ values, and the vibrational frequencies obtained at the B3LYP/6-31G(d) calculations were used with the recommended scaling factor 
Table 1. The zero point energy corrected electronic energy at $0 \mathrm{~K}, E_{\mathrm{tot}}$, the enthalpy at $298 \mathrm{~K}, H_{298}^{\mathrm{o}}$, the relative energy at $0 \mathrm{~K}$, $\Delta E_{\text {tot }}$, the enthalpy of reaction at $298 \mathrm{~K}, \Delta_{\mathrm{r}} H_{298}^{\mathrm{o}}$, the experimental enthalpy of reaction at $298 \mathrm{~K}, \Delta_{\mathrm{r}} H_{298 \text {,exptl }}^{\mathrm{o}}$, and the overall activation energy in the lowest energy pathway for the reaction from $\mathbf{2}-\mathbf{H} \mathbf{P}^{++}, \Delta E_{0}^{\text {ov }}$

\begin{tabular}{|c|c|c|c|c|c|c|c|}
\hline \multirow{2}{*}{ Species } & \multirow{2}{*}{ Ion geometry } & \multicolumn{5}{|c|}{ G3//B3LYP calculation } & \multirow{2}{*}{$\begin{array}{l}\Delta_{\mathrm{r}} H_{298, \operatorname{exptl}}^{\mathrm{o}} \\
\mathrm{kJmol}^{-1} a\end{array}$} \\
\hline & & $E_{\text {tot, }}$, hatrees & $H_{298}^{\mathrm{o}}$, hatrees & $\Delta E_{\mathrm{tot}}, \mathrm{kJmol}^{-1}$ & $\Delta E_{0}^{\mathrm{ov}}, \mathrm{kJmol}^{-1}$ & $\Delta_{\mathrm{r}} H_{298}^{\mathrm{o}}, \mathrm{kJmol}^{-1}$ & \\
\hline $2-\mathrm{HP}^{++}$ & Figure 2 & -322.9756112 & -322.969084 & 0 & & 0 & 0 \\
\hline 2-PY ${ }^{\cdot+}$ & Figure 2 & -322.9917231 & -322.985283 & -42 & 119 & -43 & -45 \\
\hline $\mathbf{P R}^{\cdot+}+\mathrm{CO}$ & Figure 1 & -322.9772158 & -322.968841 & -4 & 191 & 1 & 7 \\
\hline $\mathrm{CH}_{2}=\mathrm{CHCH}=\mathrm{C}=\mathrm{NH}^{++}+\mathrm{CO}$ & Figure S2 & -322.9344085 & -322.924660 & 108 & 323 & 117 & \\
\hline $\mathrm{CH}_{2}=\mathrm{CHCH}=\mathrm{N}=\mathrm{CH}^{+}+\mathrm{CO}$ & Figure S3 & -322.9140182 & -322.903997 & 162 & 299 & 171 & \\
\hline $\mathbf{F R}^{\cdot+}+\mathrm{HCN}$ & Figure 1 & -322.9157333 & -322.907324 & 157 & 354 & 162 & 174 \\
\hline $\mathbf{F R}^{++}+\mathrm{HNC}$ & Figure 1 & -322.8932802 & -322.884331 & 216 & 216 & 223 & 240 \\
\hline $\mathrm{CH}_{2}=\mathrm{CHCH}=\mathrm{C}=\mathrm{O}^{\cdot+}+\mathrm{HCN}$ & Figure S3 & -322.9104862 & -322.900722 & 171 & 299 & 179 & \\
\hline $\mathrm{CH}_{2}=\mathrm{CHCH}=\mathrm{C}=\mathrm{O}^{\cdot+}+\mathrm{HNC}$ & Figure S3 & -322.8880331 & -322.877729 & 230 & 238 & 240 & \\
\hline $\mathrm{c}-\mathrm{C}_{5} \mathrm{H}_{4} \mathrm{~N}^{+}+\mathrm{OH}^{\cdot}$ & Figure 1 & -322.8413282 & -322.832541 & 353 & 353 & 358 & \\
\hline
\end{tabular}

${ }^{a}$ Ref. 20.

of $0.9614 .{ }^{19}$

\section{Results and Discussion}

Although the CO loss $(\mathrm{m} / \mathrm{z} 67)$ is the only channel in the metastable ion dissociation (MID) of $\mathbf{2}-\mathbf{H P}^{\mathbf{*}},{ }^{8}$ the loss of $\mathrm{HCN}$ (or $\mathrm{HNC}, m / z 68$ ) is possible at high energies as detected in the EI spectrum, ${ }^{6}$ in which ions produced at high energies are contained. Van Tilborg and van Thuij1 ${ }^{7}$ reported that $4 \%$ of the $m / z 67$ ions formed by EI of $2-\mathrm{HP}^{2}$ are $\mathrm{C}_{4} \mathrm{H}_{3} \mathrm{O}^{+}$ ions, which must be the result of consecutive losses of $\mathrm{HCN}$ (or $\mathrm{HNC}$ ) and $\mathrm{H}^{\circ}$. It follows that the small peak at $\mathrm{m} / z 68$ in the EI mass spectrum is due to a mixture of $\mathrm{C}_{4} \mathrm{H}_{4} \mathrm{O}^{\circ+}$ and ${ }^{13} \mathrm{CC}_{3} \mathrm{H}_{5} \mathrm{~N}^{++}$ions. The energetic data are summarized in
Table $1^{20}$ for the dissociation channels examined here, which include the formation of $\mathbf{P R}^{+}$or vinyl(iso)ketenimine ions $\left(\mathrm{CH}_{2}=\mathrm{CHCH}=\mathrm{C}=\mathrm{NH}^{++}, \mathrm{CH}_{2}=\mathrm{CHCH}=\mathrm{N}=\mathrm{CH}^{++}\right)$by loss of $\mathrm{CO}$, and the formation of the furan ion $\left(\mathbf{F R}^{+}\right)$or the vinylketene ion $\left(\mathrm{CH}_{2}=\mathrm{CHCH}=\mathrm{C}=\mathrm{O}^{*+}\right)$ by loss of $\mathrm{HCN}$ or HNC.

The formation of $\mathbf{P R}^{+}+\mathrm{CO}$ is exoergic at $0 \mathrm{~K}$ and is thermodynamically the most favored among the investigated dissociation channels. Before the loss of $\mathrm{CO}, \mathbf{2}-\mathbf{H P}^{++}$tautomerizes to $\mathbf{2}-\mathbf{P Y}^{\circ+}$ by a $1,3-\mathrm{H}$ shift (Figure 1). An alternative tautomerization by two consecutive $1,2-\mathrm{H}$ shifts requires much higher energy $\left(E_{0}=358 \mathrm{~kJ} \mathrm{~mol}^{-1}\right)$ than the $1,3-\mathrm{H}$ shift $\left(E_{0}=119 \mathrm{~kJ} \mathrm{~mol}^{-1}\right)$. The loss of CO from 2-PY' $\mathbf{P Y}^{++}$occurs through two steps. According to IRC calculations, the $\mathrm{CO}$

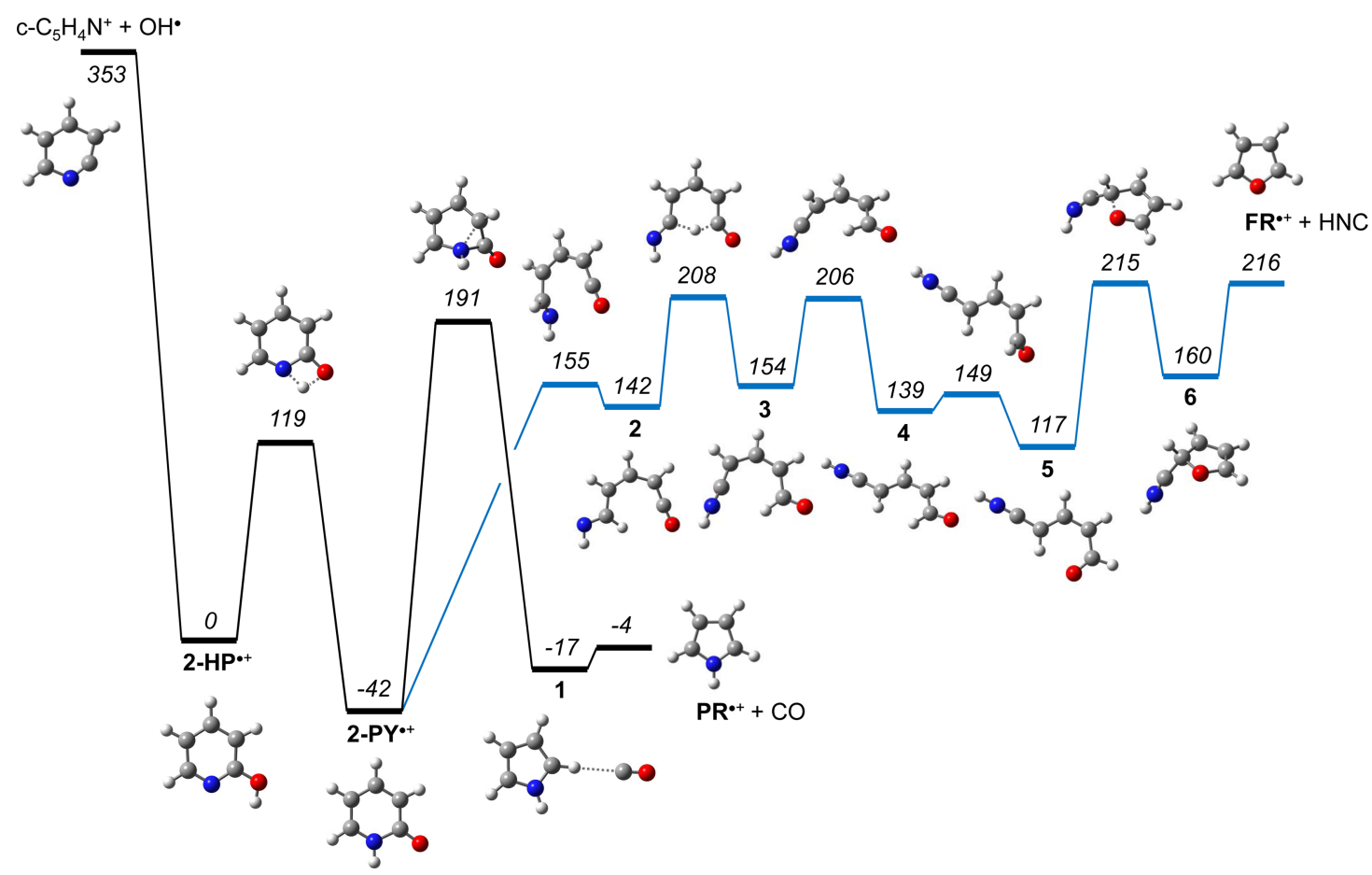

Figure 1. Potential energy diagram of the lowest energy pathway for the loss of $\mathrm{CO}, \mathrm{HNC}$, and $\mathrm{OH}^{\bullet}$ from $\mathbf{2}-\mathbf{H P}^{\bullet+}$, which was derived from G3//B3LYP calculations. The energies are presented in $\mathrm{kJ} \mathrm{mol}^{-1}$. 
moiety of 2-PY ${ }^{++}$moves away from the ring plane, and the $\mathrm{HN}-\mathrm{CO}$ bond is cleaved after surmounting the TS (see Figure 2) to form an ion-molecule complex 1, leading to the final elimination of CO. The overall activation energy $\left(E_{0}^{\mathrm{ov}}\right)$ of this dissociation from $\mathbf{2 - \mathbf { H P } ^ { + }}$ is $191 \mathrm{~kJ} \mathrm{~mol}^{-1}$. Alternatively, the isomerization $\mathbf{2}-\mathbf{P Y}^{++} \rightarrow \mathbf{1}$ may occur through a ring-opening by the $\mathrm{HN}-\mathrm{CO}$ bond rupture, rearrangements, and a five-membered ring formation (see Supplementary Figure S1). However, this pathway is far less favored than the above one-step pathway due to much higher overall activation energy of $259 \mathrm{~kJ} \mathrm{~mol}^{-1}$.

The formation of the two less stable $\mathrm{C}_{4} \mathrm{H}_{5} \mathrm{~N}^{\cdot+}$ isomers, $\mathrm{CH}_{2}=\mathrm{CHCH}=\mathrm{C}=\mathrm{NH}^{++}$and $\mathrm{CH}_{2}=\mathrm{CHCH}=\mathrm{N}=\mathrm{CH}^{+}$, by the loss of $\mathrm{CO}$ may occur though several rearrangement steps. The potential energy diagrams for their lowest energy pathways are presented in Supplementary Figures S2 and S3, respectively. The occurrence of these dissociations is negligible because their overall activation energies (323 and 299 $\mathrm{kJ} \mathrm{mol}^{-1}$, respectively) are much higher than that (191 kJ $\mathrm{mol}^{-1}$ ) for the formation of $\mathbf{P R}^{\cdot+}$.

The formation of $\mathbf{F R}^{+}+\mathrm{HNC}$ is the most favored among the losses of HCN and HNC examined, although it is thermodynamically less favored than the loss of $\mathrm{HCN}$ according to the calculated $\Delta E_{\text {tot }}$ values (Table 1). Through a ring cleavage, an $\mathrm{H}$ shift, cis-to-trans isomerizations, a fivemembered ring isomer $\mathbf{6}$ is formed, leading to the formation

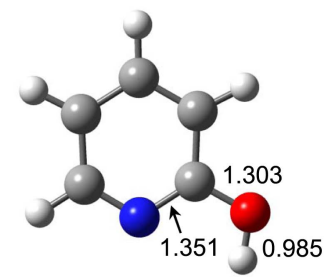

$2-\mathrm{HP}^{++}$

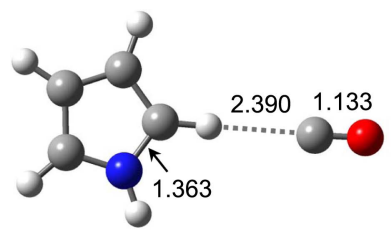

1

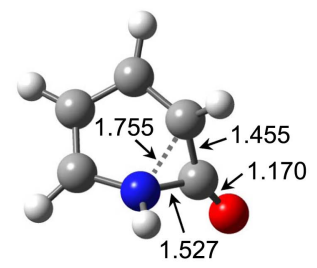

TS $2-\mathrm{PY}^{++} \rightarrow 1$

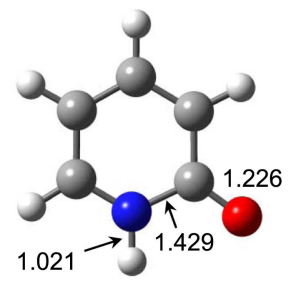

$2-\mathrm{PY}+$

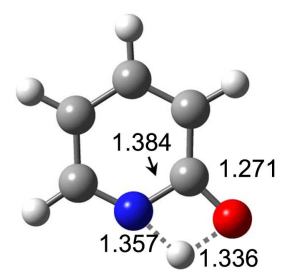

TS 2-HP++ 2-PY++

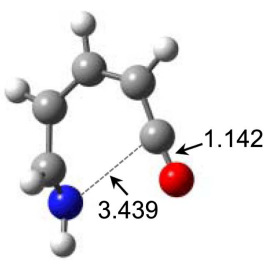

TS 2-PY.+ $\rightarrow 2$
Figure 2. Geometric structures of selected $\mathrm{C}_{5} \mathrm{H}_{5} \mathrm{~N}^{*+}$ isomers optimized by B3LYP/6-31G(d) calculations. The numbers are the bond lengths in $\AA$. of $\mathbf{F R}^{\cdot+}+\mathrm{HNC}$ (Figure 1). The overall activation energy of this dissociation is $216 \mathrm{~kJ} \mathrm{~mol}^{-1}$. This channel is the second most favored among all dissociation pathways examined. It is predicted that the other dissociations to $\mathbf{F R}^{\cdot+}+\mathrm{HCN}$, $\mathrm{CH}_{2}=\mathrm{CHCH}=\mathrm{C}=\mathrm{O}^{+}+\mathrm{HCN}$, and $\mathrm{CH}_{2}=\mathrm{CHCH}=\mathrm{C}=\mathrm{O}^{\cdot+}+\mathrm{HNC}$ rarely occur due to their high $E_{0}^{\text {ov }}$ values of 354,299 , and $238 \mathrm{~kJ} \mathrm{~mol}^{-1}$, respectively. See Supplementary Figures S5, S3, and S4, respectively, for the PESs for their lowest energy pathways. All the losses of $\mathrm{CO}, \mathrm{HCN}$, and $\mathrm{HNC}$ from 2$\mathbf{H P}^{++}$along the lowest energy pathways proceed after the tautomerization to $\mathbf{2 -} \mathbf{P Y}^{+}$. The loss of $\mathrm{OH}^{\cdot}$ may occur directly from $\mathbf{2}-\mathbf{H P}^{+}$, but is not likely to occur due to its high activation energy $\left(353 \mathrm{~kJ} \mathrm{~mol}^{-1}\right)$. All the product acyclic ions $\left(\mathrm{C}_{4} \mathrm{H}_{5} \mathrm{~N}^{\circ+}\right.$ and $\left.\mathrm{C}_{4} \mathrm{H}_{4} \mathrm{O}^{\circ+}\right)$ presented here have the cis configurations. The formations of their trans isomers are less favored because additional steps are needed for surmounting higher energy barriers.

To investigate the dissociation kinetics, the rate constants for following three reaction steps shown in Figure 1 were calculated using the RRKM formalism in Eq. (1).

$$
\begin{aligned}
& \mathbf{2 - H P}{ }^{\cdot+} \rightarrow \mathbf{2 - P Y}{ }^{\cdot+}, \quad k_{1} \\
& \mathbf{2 - P Y} \mathbf{P Y}^{+} \rightarrow \mathbf{2 - H P ^ { + + }}, \quad k_{-1} \\
& 2-\mathrm{PY}^{\bullet+} \rightarrow \mathbf{1} \\
& k_{2}
\end{aligned}
$$

$k_{2}$ is virtually the rate constant for the reaction $\mathbf{2}-\mathbf{P Y}^{++} \rightarrow$

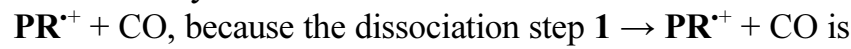
much faster than the isomerization step $\mathbf{2}-\mathbf{P Y} \mathbf{\bullet}^{+} \rightarrow \mathbf{1}$.

The rate constants thus calculated are shown in Figure 3. At the energies just above the dissociation threshold $191 \mathrm{~kJ}$ $\mathrm{mol}^{-1}$, the tautomerization rate constants, $k_{1}$ and $k_{-1}$, are more than 5 orders of magnitude larger than the dissociation rate constants, indicating that the pre-equilibrium between the keto-enol tautomers is reached before dissociation at low energies. Baldwin and Langley reported that the metastable peak for the loss of CO from $\mathbf{2}-\mathbf{H P}^{++}$was a broad dished peak without a narrow component, which was interpreted as

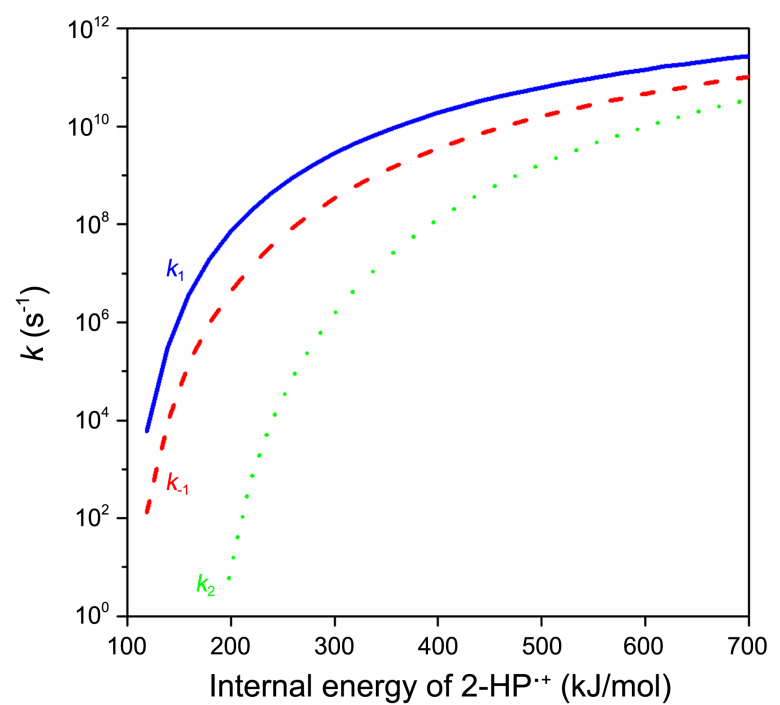

Figure 3. Energy dependence of the RRKM rate constants for reactions $2-4$ 
indicating the formation of an insignificant amount of 2$\mathbf{P Y}^{\boldsymbol{*}^{+}}$in the gas phase. ${ }^{8}$ Their interpretation is based on the assumption that the losses of CO from $\mathbf{2}-\mathbf{H P}^{++}$and $\mathbf{2}-\mathbf{P Y}^{\mathbf{+}}$ occur through different routes. However, the present mechanistic result shows that the loss of $\mathrm{CO}$ occurs only through $\mathbf{2}-\mathbf{P Y} \mathbf{r}^{++}$, even though the reaction starts from $\mathbf{2}-\mathbf{H} \mathbf{P}^{\mathbf{*}}$. In this case, their observation of a one-component metastable peak for the loss of $\mathrm{CO}$ is not evidence for the sole generation of $\mathbf{2 - H P} \mathbf{*}^{+}$by EI of 2-HP. Our calculation result indicates that the amount of $\mathbf{2 - P Y}{ }^{++}$is much larger than that of $\mathbf{2 - H P} \mathbf{P}^{+}$ above the tautomerization barrier. For example, a ratio of the relative abundances $\left[\mathbf{2}-\mathbf{P Y} \mathbf{Y}^{+}\right] /\left[\mathbf{2}-\mathbf{H P}^{++}\right]$of 25 is predicted at the $2-\mathbf{H P}^{++}$internal energy of $160 \mathrm{~kJ} \mathrm{~mol}^{-1}$, which is estimated from $k_{1} / k_{-1}$. Below the ionic tautomerization barrier, only stable ions having the structure $\mathbf{2 - \mathbf { H P } ^ { * + }}$ or $\mathbf{2 - \mathbf { P Y }}{ }^{\cdot+}$ are generated by EI of 2-HP or 2-PY, respectively. Above the tautomerization barrier and below the dissociation threshold, an ionic mixture of $\mathbf{2}-\mathbf{H} \mathbf{P}^{\boldsymbol{}^{+}}$and $\mathbf{2}-\mathbf{P Y} \mathbf{r}^{++}$is generated by EI of

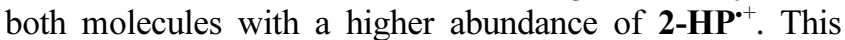
agrees with the experimental observation by Trikoupis et al. that the MID, CID, and neutralization-reionization/CID spectra of 2-HP' ${ }^{++}$and 2-PY ${ }^{\cdot+}$ are virtually identical. ${ }^{1}$

The quantitative comparison of the dissociation rates for the formations of $\mathbf{P R} \mathbf{r}^{+}+\mathrm{CO}$ and $\mathbf{F R} \mathbf{\cdot}^{++} \mathrm{HNC}$ is not simple, because the latter reaction occurs through several transition states lying at similar high energies as shown in Figure 1. Three of the four transition states between $\mathbf{2}$ and $\mathbf{6}$ lies higher than TS 2-PY ${ }^{++} \rightarrow \mathbf{1}$, indicating that the formation of $\mathbf{F R}^{\mathbf{}^{+}+}$ $\mathrm{HNC}$ is far less favored than the formation of $\mathbf{P R}^{+}+\mathrm{CO}$. The only observation of the $\mathrm{CO}$ loss in the $\mathrm{MID}^{8}$ suggests that the formation of $\mathbf{F R}^{++}+\mathrm{HNC}$ is at least 2 orders of magnitude less favored than the formation of $\mathbf{P R}^{++}+\mathrm{CO}$ on the microsecond time scale.

As the internal energy increases, the difference between the tautomerization and dissociation rate constants is diminished, indicating that the backward isomerization to 2$\mathbf{H P}^{\cdot+}$ and the dissociation compete after the formation of 2$\mathbf{P Y}^{\bullet+}$. The aforementioned formation of $\mathrm{C}_{4} \mathrm{H}_{4} \mathrm{O}^{\cdot+}$ and $\mathrm{C}_{4} \mathrm{H}_{3} \mathrm{O}^{+}$ by the EI of 2-HP indicates that the formation of $\mathbf{F R}^{\mathbf{}^{+}+}$ HNC becomes important as the internal energy increases, because fragment ions formed at high energies are also contained in EI mass spectra generally.

\section{Conclusions}

The formation of $\mathbf{P R}^{\mathbf{}^{+}}+\mathrm{CO}$ through the tautomerization to $\mathbf{2 - P Y} \mathbf{r}^{+}$is both thermodynamically and kinetically the most favorable pathway among the investigated dissociation channels of $\mathbf{2}-\mathbf{H P}^{+}$, including the loss of $\mathrm{CO}, \mathrm{HNC}$, and HCN. Our calculations show that the keto-enol tautomerization occurs very fast before dissociation at low energies, and that the relative abundance of $\mathbf{2 - P Y} \mathbf{r}^{+}$is much higher than that of $\mathbf{2}-\mathbf{H P}^{++}$at the equilibrium achieved before dissociation. The formation of $\mathbf{F R}^{-+}$is enabled by loss of HNC from $\mathbf{2}-\mathbf{H P}^{++}$at high energies, which also occurs through the tautomerization to $\mathbf{2 - P Y} \mathbf{r}^{+}$, although the dissociation yield is much smaller than the loss of CO.
Acknowledgments. This work was supported by the Supercomputing Center/Korea Institute of Science and Technology Information with supercomputing resources including technical support (KCS-2013-C1-032). The author would like to thank Hyo Joon Kim for his assistance in the preliminary calculations.

Appendix A. Supplementary data

\section{References}

1. Trikoupis, M. A.; Gerbaux, P.; Lavorato, D. J.; Flammang, R.; Terlouw, J. K. Int. J. Mass Spectrom. 2002, 217, 1-22.

2. Poully, J. C.; Schermann, J. P.; Nieuwjaer, N.; Lecomte, F.; Grégoire, G.; Desfrançois, C.; Garcia, G. A.; Nahon, L.; Nandi, D.; Poisson, L.; Hochlaf, M. Phys. Chem. Chem. Phys. 2010, 12, 3566-3572.

3. Ozeki, H.; Cockett, M. C. R.; Okuyama, K.; Takahashi, M.; Kimura, K. J. Phys. Chem. A 1995, 99, 8608-8612.

4. Galvão, T. L. P.; Rocha, I. M.; Ribeiro da Silva, M. D. M. C.; Ribeiro da Silva, M. A. V. J. Phys. Chem. A 2013, 117, 1266812674.

5. Tsuchida, N.; Yamabe, S. J. Phys. Chem. A 2005, 109, 1974-1980.

6. NIST Chemistry WebBook, NIST Standard Reference Database Number 69.

7. van Tilborg, M. W. E. M.; van Thuijl, J. Org. Mass Spectrom. 1983, 18, 331-334.

8. Baldwin, M. A.; Langley, G. J. J. Chem. Soc., Perkin Trans. II 1988, 347-350.

9. Jobst, K. J.; Khan, T. R.; Terlouw, J. K. Int. J. Mass Spectrom. 2007, 264, 146-156.

10. Yim, M. K.; Choe, J. C. J. Phys. Chem. A 2011, 115, 3087-3094.

11. Letzel, M.; Barth, D.; Kuck, D.; Grützmacher, H.-F.; Kim, S. Y.; Yim, M. K.; Choe, J. C. Int. J. Mass Spectrom. 2013, 336, 1-16.

12. Choe, J. C. Bull. Korean Chem. Soc. 2013, 34, 3249.

13. Marcus, R. A.; Rice, O. K. J. Phys. Colloid Chem. 1951, 55, 894908.

14. Baboul, A. G.; Curtiss, L. A.; Redfern, P. C. J. Chem. Phys. 1999, 110,7650 .

15. Curtiss, L. A.; Raghavachari, K.; Redfern, P. C.; Rassolov, V.; Pople, J. A. J. Chem. Phys. 1998, 109, 7764.

16. Frisch, M. J.; Trucks, G. W.; Schlegel, H. B.; Scuseria, G. E.; Robb, M. A.; Cheeseman, J. R.; Scalmani, G.; Barone, V.; Mennucci, B.; Petersson, G. A.; Nakatsuji, H.; Caricato, M.; Li, X.; Hratchian, H. P.; Izmaylov, A. F.; Bloino, J.; Zheng, G.; Sonnenberg, J. L.; Hada, M.; Ehara, M.; Toyota, K.; Fukuda, R.; Hasegawa, J.; Ishida, M.; Nakajima, T.; Honda, Y.; Kitao, O.; Nakai, H.; Vreven, T.; Montgomery, Jr., J. A.; Peralta, J. E.; Ogliaro, F.; Bearpark, M.; Heyd, J. J.; Brothers, E.; Kudin, K. N.; Staroverov, V. N.; Kobayashi, R.; Normand, J.; Raghavachari, K.; Rendell, A.; Burant, J. C.; Iyengar, S. S.; Tomasi, J.; Cossi, M.; Rega, N.; Millam, N. J.; Klene, M.; Knox, J. E.; Cross, J. B.; Bakken, V.; Adamo, C.; Jaramillo, J.; Gomperts, R.; Stratmann, R. E.; Yazyev, O.; Austin, A. J.; Cammi, R.; Pomelli, C.; Ochterski, J. W.; Martin, R. L.; Morokuma, K.; Zakrzewski, V. G.; Voth, G. A.; Salvador, P.; Dannenberg, J. J.; Dapprich, S.; Daniels, A. D.; Farkas, Ö.; Foresman, J. B.; Ortiz, J. V.; Cioslowski, J.; Fox, D. J. Gaussian 09, revision A. 02; Gaussian, Inc.: Wallingford CT, 2009.

17. Baer, T.; Hase, W. L. Unimolecular Reaction Dynamics: Theory and Experiments; Oxford University Press: New York, 1996.

18. Beyer, T.; Swinehart, D. R. ACM Commun. 1973, 16, 379.

19. Scott, A. P.; Radom, L. J. Phys. Chem. A 1996, 100, 16502-16513.

20. Lias, S. G.; Bartmess, J. E.; Liebman, J. F.; Holmes, J. L.; D., L. R.; Mallard, W. G. J. Phys. Chem. Ref. Data 1988, 17 (Suppl. No. 1). 